patients (seven women and five men) with anxiety and vestibular disturbances; their mean age of onset was 28 .

Our patients had no detectable labyrinthine disturbance, but two had other organic disturbances. One woman's left hemiparesis, thought to be due to cervical spondylosis, predisposed her to fall, but her reaction to a single fall was much greater than that of most physically handicapped people. Another (case 1) had nystagmus and directional preponderance of caloric responses, indicating a lesion at or above the left vestibular nucleus, and cervical spondylosis. These might point to the source of disturbance in all four patients.

All our patients were elderly. With age might come changes in vestibular reflexes, which might explain why adults like the violent movements of funfairs so much less than children. Our patients might have had some common unknown disturbance of the pathways subserving their visuospatial reflexes, which might be of a vestibular or other kind. This might illuminate the mechanisms that mediate anxiety symptoms like dizziness, forms of agoraphobia, and normal fears that are triggered by specific visuospatial and kinaesthetic cues-for example, fears of a visual cliff, of looking up at a skyscraper, and of the total absence of spatial cues. ${ }^{1}$

Space fears may point to another of several pathogenetic mechanisms in phobic disorders. One is the selective onset of animal phobias in young children before the age of $6,{ }^{1}$ such phobias rarely being acquired de novo in adult life. A second is the selective association of vasovagal fainting with fears of blood and injury rather than with any other kind of phobia.* Space fears seem to form a third cluster, found so far only in elderly women.

Many thanks are due to Dr A Lishman and Dr R T C Pratt, who kindly drew attention and allowed access to one of their patients (case 1) at the National Hospital, Queen Square. They made valuable comments on the manuscript, as did Drs R Kumar and R Stern.

\section{References}

${ }^{1}$ Marks, I M, Fears and Phobias. London, Heinemann Medical, 1969.

2 Kerry, R J, Fournal of Mental Science, 1960, 106, 1383.

${ }^{3}$ Klein, D F, Psychopharmacologia, 1964, 5, 397.

Tyrer, P J, Candy, J, and Kelly, D H W, Psychological Medicine, 1973, 3, 120.

${ }^{5}$ Lipsedge, M, et al, Psychopharmacologia, 1973, 32, 67.

6 Benedikt, M, Allgemeine Wiener medizinische Zeitung, 1870, 15, 488.

${ }^{7}$ Pratt, R T C, and McKenzie, W, Lancet, 1968, 2, 347.

${ }^{8}$ Connolly, J, Hallam, R, and Marks, I M, Behaviour Therapy, 1976, 7, 8.

\title{
Detection of renal anomalies by abdominal palpation in newborn infants
}

\author{
M PERLMAN, J WILLIAMS
}

We report a series of such anomalies and the technique of palpation used to detect them.

\section{Summary}

In a new technique of palpation for renal anomalies in the newborn one hand supports the infant while the fingers of the other hand support the loin and the thumb explores the abdomen. In a series of 11000 otherwise normal newborn children superficial palpation detected 11 renal anomalies, and deep palpation led to the discovery of another 42 anomalies. One of two other series in which palpation was performed bimanually gave a similar incidence of renal anomalies (0.5 $\left.{ }_{0}\right)$. Early discovery of an asymptomatic anomaly enables early treatment of the complications that are often found in patients with congenital renal anomalies detected in later life.

\section{Introduction}

Careful abdominal palpation at the routine newborn examination can yield an incidence of renal anomalies of $0.5 \%{ }^{1}$; early diagnosis is important because of subsequent complications. ${ }^{2-9}$

Neonatal Unit, Soroka Medical Centre, Beer Sheva, Israel M PERLMAN, MRCP, physician in charge (now physician in charge, neonatal unit, Hadassah University Hospital, Jerusalem, Israel)

J WILLIAMS, MRCP, senior paediatric resident (now fellow in neonatology, Baylor College of Medicine, Houston, Texas 77025, USA)

\section{Patients and methods}

Over 42 months we examined 11415 infants during the first three days after birth. We did not intend to conclusively palpate the kidneys of every infant examined, though we achieved this in about $95^{\circ}$ of the babies (about 11000 infants).

The kidneys were examined as follows. The infant was supported in a semi-reclining position facing the examiner by a hand behind his shoulders, neck, and occiput (fig 1). Alternatively the abdomen may be relaxed by flexing the lower limbs of the prone infant while lifting the buttocks off the bed (fig 2). The fingers of the opposite hand supported the matching loin posteriorly while the thumb searched that side of the abdomen systematically, at first superficially and then deeply. Deep palpation was performed by applying gentle, steadily increasing pressure subcostally in a posterior and cephalad direction. The thumb was then slid downwards without reducing the posteriorly directed pressure. Usually the upper pole of the kidney was felt trapped between the descending thumb and the posteriorly placed fingers. While mild traction was exerted on the kidney it slipped cephalad under the thumb, and during this passage its shape and extent could be appreciated. The opposite side of the abdomen was examined by changing hands.

The technique was mastered after examining about 20 infants, took 30 seconds, and was facilitated by the hypotonia of the abdominal muscles during the first days after birth.

The urine was examined in most infants with renal anomalies. The possibility of renal trauma raised by other workers ${ }^{110}$ was evaluated by examining the first urine specimen (midstream) passed after deep palpation of the kidneys of 20 normal male babies.

In all cases the clinical diagnosis was confirmed by intravenous urography or renal scan, or both. Urography was the preferred investigation for clinically enlarged kidneys while renal scan was performed 


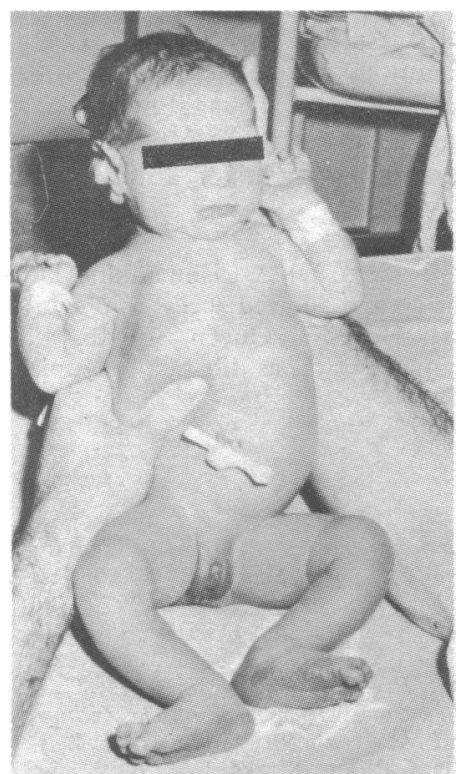

FIG 1-Posture of infant during deep palpation of right kidney.

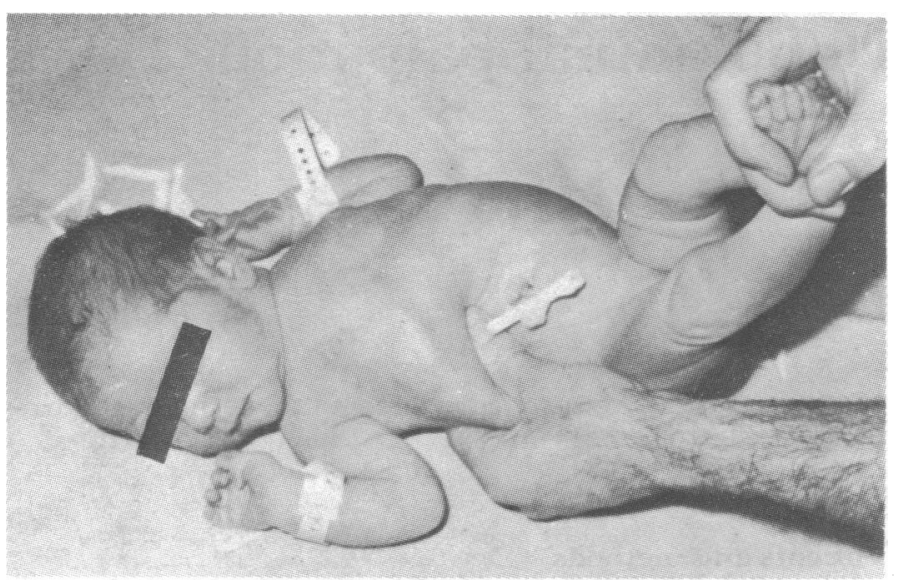

FIG 2-Another method of relaxing abdominal wall muscles.

more often as an initial investigation of apparent absence of the kidney or change in shape.

\section{Results}

Renal anomalies were suspected on palpation in 82 otherwise normal infants. Eleven were lost to follow-up, and the diagnosis of a renal anomaly was confirmed in 51 of the 71 infants investigated (tables I and II). During the same period renal anomalies accompanied

TABLE I-Data relating to clinical diagnoses and diagnostic accuracy

\begin{tabular}{r|c|c|c|c|c}
\hline Clinical category & $\begin{array}{c}\text { Anomalies } \\
\text { detected } \\
\text { clinically }\end{array}$ & $\begin{array}{c}\text { No of } \\
\text { infants } \\
\text { lost to } \\
\text { investiga- } \\
\text { tion }\end{array}$ & $\begin{array}{c}\text { No of } \\
\text { anomalies } \\
\text { investiga- } \\
\text { ted }\end{array}$ & $\begin{array}{c}\text { No } \\
\text { con- } \\
\text { firmed }\end{array}$ & $\begin{array}{c}\% \\
\text { Positive }\end{array}$ \\
\hline $\begin{array}{r}\text { Gross renal enlargement } \\
\text { Deeply detected renal }\end{array}$ & 11 & 0 & 11 & 11 & 100 \\
enlargement ... & 16 & 1 & 15 & 3 & 20 \\
Unilaterally impalpable & 40 & 8 & 32 & 27 & 84 \\
Altered shape .. ... & 17 & 2 & 15 & 12 & 80 \\
\hline Total ... & 84 & 11 & 73 & $53 *$ & 73 \\
\hline
\end{tabular}

*Includes two patients with bilaterally different anomalies that were recognised individually.
TABLE II-Frequency of renal anomalies detected by physical examination

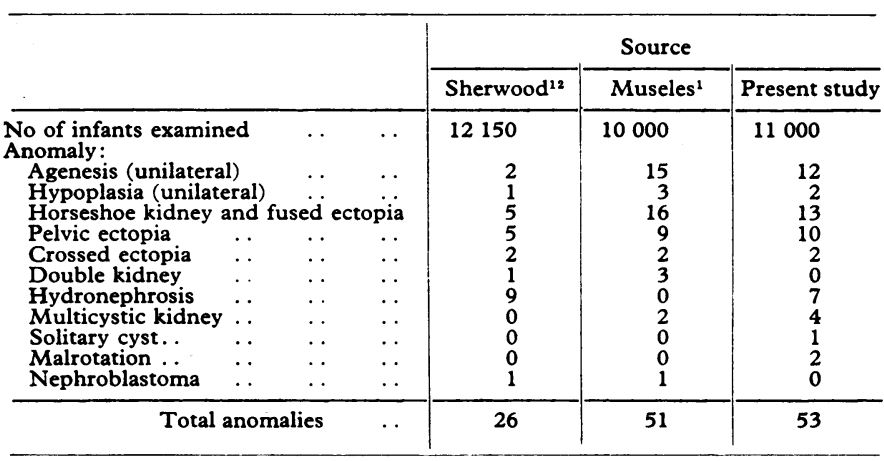

by defects in other systems were diagnosed in 18 infants, and they were omitted from this series. Four infants with unilateral adrena haemorrhage were also excluded.

Superficial palpation detected seven cases of hydronephrosis and four of multicystic kidney (one patient had one of each of the anomalies). Three patients with hydronephrosis and two with multicystic kidney had microscopic haematuria. Intravenous urography was used for the 10 patients with gross renal enlargement. Deep palpation led to the discovery of anomalies in 41 infants. These were divided into three clinical categories.

Mild renal enlargement. Most cases of suspected mild enlargement proved to be false-positives (table I). Fourteen intravenous pyelographies and five renal scans were performed in 15 patients. The renal enlargement noted in two cases of malrotation was in fact spurious. Most examples in this category occurred in the earlier part of the study.

Unilateral impalpable kidney was due to unilateral agenesis and hypoplasia, and pelvic, crossed, and fused ectopia. Agenesis was presumed if the kidney was impalpable and functioning renal tissue was not detected on scan or urography. Renal scans were performed in 26 patients and urography in 10. Ancillary investigations confirmed our suspicions of an abnormality in $84 \%$ of infants in whom we could not feel a kidney.

Changed renal shape was found in all those with horseshoe kidneys and in most cases of fused ectopia. The position of one or both of the fused kidneys was either inferior or medial to the normal position. Eleven patients were submitted to renal scan and six to intravenous urography. Investigations confirmed an abnormality in $80 \%$ of cases.

\section{URINE ANALYSIS AND MICROSCOPY OF URINE}

In most cases urine was first examined on the third day after birth. Traces of protein were detected in three out of 20 specimens of urine from controls and epithelial casts in two specimens.

Three of the seven infants with hydronephrosis had microscopic haematuria and one of them had pyuria and a positive culture on the fifth day after birth. Of the four infants with a multicystic kidney, two had microscopic haematuria. Among the infants with deeply palpable anomalies a midstream specimen of urine was obtained in 18 boys and a urine collection bag specimen in 14 girls. Two boys had proteinuria and epithelial casts, and microscopic haematuria was found in one with horseshoe kidney. As expected there was a high incidence of contamination of the girls' urine by epithelial cells and debris. No infant had a significantly positive urine culture.

\section{Discussion}

The value of diagnosing an asymptomatic renal anomaly in a well newborn infant lies in the anticipation and early treatment of subsequent complications. Congenital malformations of the urogenital tract occur in about $12 \%$ of newborn infants. ${ }^{11}$ At least $0.5 \%$ of infants have renal malformations, ${ }^{1}$ most of which are clinically detectable only by deep palpation.

The method of deep palpation we used is a variation of the bimanual technique. ${ }^{12}$ The advantages of using one hand are the release of the other for good positioning of the infant and 
improved proprioception between digits of the same hand compared with that between digits of opposite hands. The technique is easily mastered if attention is paid to pacifying the infant and maintaining a relaxed posture. Pressure applied to the abdomen should be steady but not excessive so that the infant remains quiet throughout the examination. The result of the examination is inconclusive in a small percentage of cases.

False-positive clinical diagnosis of a renal anomaly occurred in 20 of our infants; in 12 mild inequality of renal size gave the impression of mild unilateral renal enlargement. Most of these unconfirmed examples of renal enlargement occurred in the earlier part of the study. As we became more experienced mild inequality of renal size was accepted as normal. False-negative diagnoses did not come to our attention in the same hospital during or after the study. A few infants with potentially palpable renal anomalies were probably missed.

Table II compares the incidence of the different anomalies in this and two other series. ${ }^{12}$ Our overall incidence of $0.5 \%$ is similar to that of Museles et al, ${ }^{1}$ and in both studies the commonest anomalies were unilateral agenesis, pelvic ectopia, and horseshoe kidney. Hydronephrosis was relatively common in our series and that of Sherwood $e t a l^{12}(0.06 \%$ and $0.07 \%$ respectively) but was not diagnosed in the series of Museles et al.

In practice the deeply palpated renal anomaly is mostly undetected in the newborn period and is diagnosed as a result of complications occuring later in childhood or in adult life. Examination of the urine gave mainly negative results immediately after birth, especially in infants with the less easily palpated renal anomalies and therefore seems not to be a useful screening procedure in this age group. Retrospective clinical and necropsy studies $^{2-9}$ show that pyelonephritis, calculi, hypertension, hydronephrosis, nephroblastoma, and renal adenocarcinoma are associated with unilateral agenesis or hypoplasia, ectopia, malrotation and horseshoe kidney. For example, in 31 patients with unilateral agenesis ${ }^{5}$ eight had hydronephrosis (without calculi), six had calculi, two had isolated urinary infection, and one had pain from ectopia of the single kidney, leaving 14 free of complications. Another series of 51 patients with horseshoe kidney $^{6}$ included only 14 patients without complications; and 20 cases of nephroblastoma in a horseshoe kidney have been reported. ${ }^{9}$

Follow-up in the newborn infant with a renal anomaly should therefore be directed towards detecting complications by urine examinations, blood pressure measurements, and regular abdominal palpation, with further investigation as required. Until prospective follow-up of these anomalies is undertaken from the newborn period, the numerical risk of complications will remain uncertain.

\section{References}

${ }^{1}$ Museles, M, Gaudry, C L, jun, and Bason, W M, Pediatrics, 1971, 47, 97.

2 Berant, M, Jacob, E T, and Pevzner, S, Journal of Pediatric Surgery, 1975, $10,555$.

${ }^{3}$ Campbell, M F, and Harrison, J H (editors), Urology, 3rd edn, vol 2, p 1419. Philadelphia, Saunders, 1970.

4 Campbell, M F, and Harrison, J H (editors), Urology, 3rd edn, vol 2, p 1460. Philadelphia, Saunders, 1970.

5 Dees, J E, fournal of Urology, 1960, 83, 550.

6 Glenn, J F, New England fournal of Medicine, 1959, 261, 684.

7 Langworthy, H T, and Drexler, L S, fournal of Urology, 1942, 47, 776.

${ }^{8}$ Lee, H P, fournal of Urology, 1949, 61, 333.

9 Shashikumar, V L, et al, fournal of Pediatric Surgery, 1974, 9, 185.

${ }^{10}$ Yearbook of Pediatrics, 1972, ed S S Gellis, p 226. Chicago, Yearbook Medical Publishers, 1972.

11 Campbell, M F, Pediatric Clinics of North America, 1955, 2, 653.

12 Sherwood, D W, et al, Pediatrics, 1956, 18, 782.

\title{
Pseudomonas aeruginosa infections associated with use of contaminated medicaments
}

\author{
ROSAMUND M BAIRD, R A SHOOTER
}

British Medical fournal, 1976, 2, 349-350

\section{Summary}

Pseudomonas aeruginosa was recovered from three hospital-prepared medicaments being used on the wards. Sixty-six patients were studied to observe the effect of using these contaminated medicaments. Ps aeruginosa was recovered from 29 patients; in five the strains recovered bore a close resemblance to strains previously isolated from the contaminated medicaments.

\section{Introduction}

Pharmaceutical products made in the hospital may become contaminated with strains of Pseudomonas aeruginosa from the pharmacy environment. ${ }^{1}$ In one hospital pharmacy medicaments

Department of Medical Microbiology and Pharmacy, St Bartholomew's Hospital, London EC1A 7BE

ROSAMUND M BAIRD, PHD, principal pharmacist

R A SHOOTER, FRCP, FRCPATH, professor of medical microbiology contaminated with Ps aeruginosa were inadvertantly issued to the wards, and we attempted to trace the routes by which patients may have acquired strains of Ps aeruginosa from these medicaments.

\section{Methods}

Nine wards of the hospital were examined over two months. Three medicaments in the wards (pine disinfectant, chlorxylenol disinfectant, and a handcream), the ward environment, and the patients were examined for Ps aeruginosa. Patients examined included those with known pseudomonas infections, patients in adjacent beds to those with infections, and patients with bedsores or open wounds. The disinfectants were used in the wards for cleaning floors, lavatories, sinks, and baths. The handcream was used only by the nurses.

\section{CULTURAL METHODS}

Medicaments-1 ml or $1 \mathrm{~g}$ was incubated overnight at $37^{\circ} \mathrm{C}$ in $20 \mathrm{ml}$ of nutrient broth containing $4 \%$ Lubrol $\mathrm{W}$ and then subcultured to $0.03 \%$ cetrimide agar.

Environmental sites-Mops, buckets, cloths, and handmops were sampled with moistened swabs, incubated overnight in nutrient broth, and then subcultured to cetrimide agar. 